\title{
Disruption of the 12/15-lipoxygenase gene diminishes atherosclerosis in apo $\mathrm{E}$-deficient mice
}

\author{
Tillmann Cyrus, ${ }^{1}$ Joseph L. Witztum, ${ }^{2}$ Daniel J. Rader, ${ }^{3}$ Rajendra Tangirala, ${ }^{3}$ \\ Sergio Fazio, ${ }^{4}$ MacRae F. Linton, ${ }^{4}$ and Colin D. Funk ${ }^{1}$ \\ ${ }^{1}$ Center for Experimental Therapeutics, University of Pennsylvania, Philadelphia, Pennsylvania 19104, USA \\ ${ }^{2}$ Department of Medicine, University of California-San Diego, San Diego, California 92093, USA \\ ${ }^{3}$ Division of Cardiovascular Medicine, Department of Medicine, University of Pennsylvania, \\ Philadelphia, Pennsylvania 19104, USA \\ ${ }^{4}$ Division of Endocrinology and Diabetes, Department of Medicine, Vanderbilt University School of Medicine, \\ Nashville, Tennessee 37232, USA \\ Address correspondence to: Colin D. Funk, Center for Experimental Therapeutics, 422 Curie Boulevard, Room 806, \\ University of Pennsylvania, Philadelphia, Pennsylvania 19104-6100, USA. Phone: (215) 898-0254; \\ Fax: (215) 573-9004; E-mail: colin@spirit.gcrc.upenn.edu
}

Received for publication November 25, 1998, and accepted in revised form May 3, 1999.

\begin{abstract}
Atherosclerosis may be viewed as an inflammatory disease process that includes early oxidative modification of LDLs, leading to foam cell formation. This "oxidation hypothesis" has gained general acceptance in recent years, and evidence for the role of lipoxygenases in initiation of, or participation in, the oxidative process is accumulating. However, the relative contribution of macrophage-expressed lipoxygenases to atherogenesis in vivo remains unknown. Here, we provide in vivo evidence for the role of $12 / 15$-lipoxygenase in atherogenesis and demonstrate diminished plasma IgG autoantibodies to oxidized LDL epitopes in 12/15-lipoxygenase knockout mice crossbred with atherosclerosis-prone apo E-deficient mice (apo $E^{-/-} / L-12 \mathrm{LO}^{-/-}$). In chow-fed 15 -week-old apo $\mathrm{E}^{-/-} / \mathrm{L}-12 \mathrm{LO}^{-/-}$mice, the extent of lesions in whole-aorta en face preparations $\left(198 \pm 60 \mu \mathrm{m}^{2}\right)$ was strongly reduced $(P<0.001, n=12)$ when compared with 12/15-lipoxygenase-expressing controls (apo $\left.E^{-/-} / L-12 \mathrm{LO}^{+/+}\right)$, which showed areas of lipid deposition $\left(15,700 \pm 2,688 \mu \mathrm{m}^{2}\right)$ in the lesser curvature of the aortic arch, branch points, and in the abdominal aorta. These results were observed despite cholesterol, triglyceride, and lipoprotein levels that were similar to those in apo E-deficient mice. Evidence for reduced lesion development was observed even at 1 year of age in apo $E^{-/-} / L-12 \mathrm{LO}^{-/-}$mice. The combined data indicate a role for $12 / 15$ lipoxygenase in the pathogenesis of atherosclerosis and suggest that inhibition of this enzyme may decrease disease progression.
\end{abstract}

J. Clin. Invest. 103:1597-1604 (1999).

\section{Introduction}

Atherosclerosis, the underlying cause of myocardial infarction, stroke, and vascular occlusive disease of the extremities, is the leading cause of mortality in the United States (1). Considerable evidence has accumulated in recent years to support the hypothesis that LDL oxidation plays an important role in atherogenesis (2-4). This so-called "LDL oxidation hypothesis" arose from initial data indicating that endothelial cells (5-7), smooth muscle cells $(7,8)$, and macrophages (9) could oxidatively modify LDL in vitro, enabling its uptake by macrophages and leading to foam cell formation. Other studies have shown the presence of oxidatively modified LDL (oxLDL) and oxidized lipids in atheromatous tissue, including fatty acid and cholesteryl ester hydroperoxides (10-12). OxLDL is immunogenic, and autoantibodies to it are present in animal and human serum $(13,14)$. Furthermore, distinct markers of oxidative stress, known as isoprostanes, are associated with atherosclerotic lesion development $(15,16)$, and vitamin $\mathrm{E}$ is able to suppress lesion development and isoprostane levels in atherosclerotic-prone mice (17).

OxLDL promotes atherogenesis by many potential mechanisms $(18,19)$. For instance, it contributes to monocyte recruitment into developing lesions and its retention there (19-22). It also profoundly affects gene expression of vascular wall cells, leading to changes in chemokine and cytokine responses. Cytokines, in turn, modulate LDL oxidation in activated monocytes (23). OxLDL also regulates macrophage gene expression through ligand activation of the peroxisome proliferator-activated receptor $\gamma$ (PPAR- $\gamma$; ref. 24).

The mechanisms for generation of oxLDL in vivo have been debated. Among the potential candidates are lipoxygenase enzymes $(25,26)$. Lipoxygenases are a family of non-heme iron-containing dioxygenases that insert molecular oxygen into polyenoic fatty acids (27, 28). Human and rabbit 15-lipoxygenases, as well as porcine "leukocyte-type" 12-lipoxygenase (L-12LO), are capable of directly oxygenating esterified fatty acids in lipoproteins (cholesteryl esters) and phospholipids (26, $29,30)$. These particular enzymes can be classified as 12/15-lipoxygenases because they form both 12hydroperoxy-eicosatetraenoic acid (12-HPETE) and 15HPETE from arachidonic acid (in various ratios) and predominantly 13-hydroperoxy-octadecadienoic acid (13-HPODE) from linoleic acid $(27,28)$. 15-lipoxygenase and L-12LO are closely related, and subtle amino acid substitutions can account for the species differences 


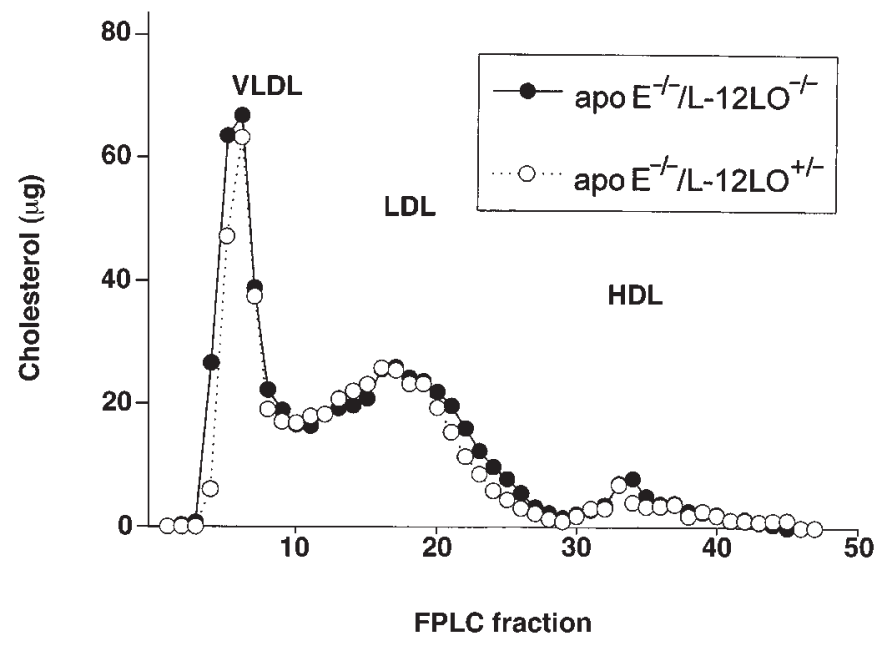

\section{Figure 1}

Lipoprotein profiles in apo E-deficient mice are not altered by 12/15-lipoxygenase deficiency. Representative plasma lipoprotein profiles of apo $E^{-/-} / L-12 L^{-/-}$double-knockout mice and apo $E^{-/-} / L-12 L^{+/-}$control mice. Pooled plasmas from two or three 15week-old mice on chow diet $(n=2-4)$ were fractionated by FPLC, using 2 Superose 6 columns in series. Fractions were then assayed for cholesterol in duplicates. All values are expressed as micrograms per fraction per $100 \mu \mathrm{L}$ of plasma. (human and rabbit 15-lipoxygenase versus pig, mouse, and rat L-12LO) by altering the ratio of 12-HPETE to 15HPETE metabolites (31-33).

15-lipoxygenase colocalizes with epitopes of oxLDL in human and rabbit atherosclerotic lesions (34-36), and stereospecific lipoxygenase products have been demonstrated in early atherosclerotic lesions of rabbits and humans (37-39). However, there is evidence for both pro- and antiatherogenic activity of 12/15-lipoxygenase (40-44).

Based on the proatherogenic properties, disruption of 12/15-lipoxygenase expression might be expected to reduce oxidative modification of LDL by macrophages and to result in decreased foam cell formation and inhibition of the early stages of atherosclerotic lesion development. To test this hypothesis, we crossbred 12/15-lipoxygenase-deficient mice (also referred to as L-

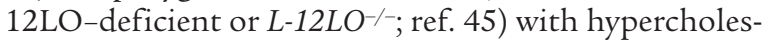
terolemia- and atherosclerosis-prone apo E-deficient mice (apo $\left.E^{-/-}\right)(46)$ and analyzed aortic lesion development. Our results suggest a proatherogenic role for $12 / 15$-lipoxygenase in this model.

\section{Methods}

Generation of apo $E^{-/-} / \mathrm{L}-12 \mathrm{LO}^{-/-}$double-knockout mice. Apo E-deficient mice on the C57BL/ 6 genetic background were obtained from The Jackson Laboratory (Bar Harbor, Maine, USA). The generation of L-12LO-deficient mice was previously described (45). They were backcrossed 7 times to C57BL/6 and were crossbred with apo $E^{-/-}$mice. Mice were genotyped either by PCR analysis (apo E) or Southern blot analysis (L-12LO) as described $(45,46)$. All mice were kept on a 12 -hour light/12-hour dark cycle and were fed a normal mouse-chow diet (RP5015; PMI Feeds Inc., St. Louis, Missouri, USA). Food and water were available ad libitum. All animal procedures were carried out in accordance with institutional and National Institutes of Health guidelines.

L-12LO activity assay and reverse-phase HPLC. Resident peritoneal macrophages were harvested (45) into Dulbecco's PBS containing $1 \mathrm{mg} / \mathrm{mL}$ BSA. The cells were incubated with 100 $\mu \mathrm{M}$ arachidonic acid at $37^{\circ} \mathrm{C}$ for 15 minutes. Samples were extracted with octadecylsilyl-silica (ODS-silica) columns (Millipore Corp., Bedford, Massachusetts, USA) and separated by reverse-phase HPLC (RP-HPLC) (Series 1050 HPLC system; Hewlett-Packard, Palo Alto, California, USA) using a Phenomenex ODS-silica column and a solvent system consisting of acetonitrile/methanol /water/acetic acid (350:150:250:1; $\mathrm{vol} / \mathrm{vol}$ ) at a flow rate of $1.5 \mathrm{~mL} / \mathrm{min}$. The effluent was monitored by ultraviolet absorption at $235 \mathrm{~nm}$ to detect hydroxyeicosatetraenoic acid (HETE) compounds.

Quantitation of atherosclerosis. Mice were anaesthetized and bled via cardiac puncture. Perfusion-fixation and preparation of the aortas were done as described previously (13). For the en face preparations, images of Sudan IV-stained aortas were captured with a Sony DXC-960MD color video camera, and image analysis was performed using Optimas 4.0 image analysis software (Bioscan, Seattle, Washington, USA). Alternate $10-\mu \mathrm{m}$ frozen sections covering $300 \mu \mathrm{m}$ of the proximal aorta, starting at the aortic sinus, were stained for atherosclerotic lesions with oil red O (47). Image analysis was performed using the Kontron 400 software (Carl Zeiss Jena GmbH, Jena, Germany).

Lipid and HPLC analysis. Plasma triglyceride and total cholesterol levels were determined via an automated enzymatic technique (Boehringer Mannheim GmbH, Mannheim, Germany). Mouse lipoproteins were separated by fast protein liquid chromatography (FPLC) analysis of plasma using 2 Superose 6 columns in series (Pharmacia Biotech Inc., Piscataway, New Jersey, USA). Aliquots of mouse plasma $(100 \mu \mathrm{L})$ were injected onto the column, separated with a buffer containing $0.15 \mathrm{M}$ $\mathrm{NaCl}, 0.01 \mathrm{M} \mathrm{Na}_{2} \mathrm{HPO}_{4}$, and $0.1 \mathrm{mM}$ EDTA (pH 7.5) at a flow rate of $0.5 \mathrm{~mL} / \mathrm{min}$, and analyzed for lipids.

Immunohistochemistry. Immunostaining sections for macrophage content was performed with the avidin-biotinalkaline phosphatase method (Vector Laboratories, Burlingame, California, USA; and Boehringer Mannheim $\mathrm{GmbH}$ ), using rat mAb to mouse macrophages (MOMA-2; Accurate Chemical and Scientific Corp., Westbury, New York, USA) diluted in PBS 1:30 (48). A rabbit polyclonal antibody against mouse $\mathrm{L}-12 \mathrm{LO}$ was generated against an $\mathrm{NH}_{2}$-terminal, 6-histidine-tagged, full-length fusion protein purified from baculovirus-infected $S f 9$ insect cells. The IgG fraction was purified using affinity chromatography isolation with Protein A (Pierce Chemical Co., Rockford, Illinois, USA). Cryosections (5 $\mu \mathrm{m})$ were immunostained with this polyclonal antibody at a dilution of 1:50, using the avidin-biotin-horseradish peroxidase method (Vector Laboratories).

Determination of autoantibody titers against oxLDL epitopes. The titers of autoantibodies to oxLDL and malondialdehyde-modified LDL (MDA-LDL) were determined in individual plasma samples of apo $E^{-/-} / \mathrm{L}-12 \mathrm{LO}^{-/-}$and apo $E^{-/-} / \mathrm{L}-12 \mathrm{LO}^{+/-}$mice using a highly sensitive chemiluminescent detection system (14). Copper oxLDL and MDA-LDL were plated as antigens on microtiter wells, and a 1:500 dilution of mouse plasma was added. The 


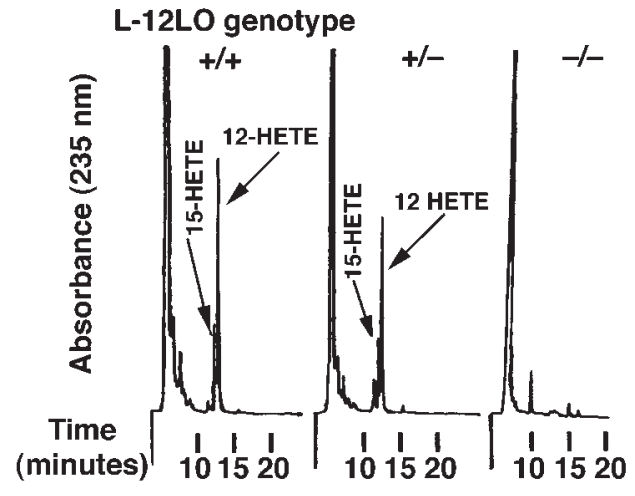

amount of $\operatorname{IgG}$ or IgM was then detected with alkaline phosphatase-labeled anti-mouse IgG or IgM. Data are expressed as relative light units per 100 milliseconds (RLU/100 ms).

Statistical analysis. Initial analyses were performed by the Student's $t$ test. If the data did not fit the constraints of this parametric test, data were analyzed with Kruskal-Wallis ANOVA or the Mann-Whitney test. $P<0.05$ was considered significant. Correlations between autoantibody titers and the extent of en face lesions were determined by linear regression analysis. Instat 2.01 software (Instat Computer Software, San Diego, California, USA) was used for all calculations. All data are presented as mean \pm SEM.

\section{Results}

Apo $E^{-/-} / \mathrm{L}-12 \mathrm{LO}^{-/-}$double-knockout mice: lipid profiles and 12lipoxygenase activity. Apo E-deficient mice have marked hypercholesterolemia and develop atherosclerotic lesions in the aortic root and throughout the entire aorta in a reproducible, time-dependent manner, even when fed a normal chow diet $(46,49)$. Atherosclerosis in these mice appears to be oxidation dependent $(13,17)$, and they develop elevated titers of $\operatorname{IgG}$ autoantibodies to epitopes of oxLDL (13). $\mathrm{L}-12 \mathrm{LO}^{-/}$mice were backcrossed to the C57BL/ 6 background 7 times and were crossbred with mice lacking apo $\mathrm{E}\left(\right.$ apo $\left.E^{-/-}\right)$. Double-knockout (apo $E^{-/-} / L^{-}$ $\left.12 \mathrm{LO}^{-/-}\right)$mice were fertile and outwardly healthy. All animals were maintained on a normal chow diet and gained weight in a similar manner (data not shown). At 15 weeks of age, all apo $E^{-/-}$mice either completely deficient in L$12 \mathrm{LO}\left(\mathrm{L}-12 \mathrm{LO}^{-/-}\right)$, heterozygous for the $\mathrm{L}-12 \mathrm{LO}$ mutant allele $\left(L-12 \mathrm{LO}^{+/-}\right)$, or wild-type $\left(L-12 \mathrm{LO}^{+/+}\right)$had similar plasma levels of triglycerides and cholesterol (Table 1 ). Moreover, the lipoprotein profile showed almost identical distribution between the VLDL, LDL, and HDL cholesterol fractions of apo $E^{-1-} / L-12 \mathrm{LO}^{-/-}$and apo $E^{-/-} / \mathrm{L}-12 \mathrm{LO}^{+/-}$mice (Figure 1). Macrophages from double-knockout mice were incapable of generating 12-hydroxy-eicosatetraenoic acid (12-HETE) and 15-HETE from arachidonic acid, whereas macrophages from apo $E^{-/-} / L-12 L O^{+/-}$and apo $E^{-/-} / L^{-}$ $12 \mathrm{LO}^{+/+}$mice synthesized both products (Figure 2).

Lack of 12/15-lipoxygenase results in diminished lesion development in apo E-deficient mice. Atherosclerotic lesion development was determined in aortic preparations beginning directly distal to the aortic valve, extending into the proximal parts of the major branching arteries, and ending about $1 \mathrm{~cm}$ behind the iliac bifurcation (en face preparations; Figure 3a). The average (arithmetic mean) size of the atherosclerotic lesions in the apo $E^{-/-} / \mathrm{L}-12 \mathrm{LO}^{-/}$doubleknockout mice $\left(198 \pm 60 \mu \mathrm{m}^{2}\right)$ was significantly reduced when compared with apo $E^{-/-} / \mathrm{L}-12 \mathrm{LO}^{+/+}$single-knockout mice $\left(15,700 \pm 2,688 \mu \mathrm{m}^{2} ; P<0.0001\right.$, t test $)$ and apo $E^{-1-} / L$ $12 \mathrm{LO} \mathrm{O}^{+/-}$mice $\left(15,045 \pm 3,134 \mu \mathrm{m}^{2} ; P<0.0001\right)$ (Figure $3 \mathrm{~b}$ ). There was no correlation between lesion size and plasma cholesterol concentration in the apo $E^{-/ /} / \mathrm{L}^{-12} \mathrm{LO}^{-/-}$double-knockout mice, the apo $E^{-/ /} / L-12 \mathrm{LO}^{+/+}$single-knockout mice, or apo $E^{-/-} / \mathrm{L}-12 \mathrm{LO} \mathrm{O}^{+/-}$heterozygous littermates.

Quantitation of lesion areas by section analysis in the proximal aorta was performed in the region using the first $300 \mu \mathrm{m}$ of the proximal aorta, starting at the aortic sinus and evaluating alternate $10-\mu \mathrm{m}$ sections. As in the en face analysis, significantly reduced lesion development was detected between apo $E^{-/-} / \mathrm{L}-12 \mathrm{LO}^{-/-}$doubleknockout mice $\left(22,835 \pm 5,788 \mu \mathrm{m}^{2} ; n=12\right)$ and apo $E^{-/ /} / \mathrm{L}-12 \mathrm{LO}^{+/+}$mice $\left(61,944 \pm 15,164 \mu \mathrm{m}^{2} ; n=9, P=\right.$ 0.015 , Mann-Whitney test), and near borderline significance was detected with apo $E^{-/-} / \mathrm{L}-12 \mathrm{LO}^{+/-}$mice $(50,296$ $\pm 14,779 \mu \mathrm{m}^{2} ; n=12, P=0.10$, Mann-Whitney test). There was no significant difference between apo $E^{-/-} / L$ $12 \mathrm{LO}^{+/+}$and apo $E^{-/-} / \mathrm{L}-12 L \mathrm{~L}^{+/-}$mice $(n=12 ; P=0.60, t$ test) (Figure 3c).

The aortic sinus lesions from all $\mathrm{L}-12 \mathrm{LO}^{-/-}, \mathrm{L}-12 \mathrm{LO}^{+/-}$, and $L-12 \mathrm{LO}^{+/+}$mice on an apo $E^{-/-}$background consisted mainly of foamy macrophages. Immunohistochemical studies showed that these macrophages stained positive with the anti-mouse macrophage mAb MOMA-2 and with a polyclonal antibody against $\mathrm{L}-12 \mathrm{LO}\left(\mathrm{L}-12 \mathrm{LO}^{+/+}\right.$and $\left.L-12 \mathrm{LO}^{+/-}\right)$- whereas apo $E^{-/-} / \mathrm{L}-12 \mathrm{LO}^{-/}$double-knockout macrophages stained positive only with MOMA-2 - but were negative for L-12LO expression (Figure 4). Only $\sim 40 \%$ of lavaged resident peritoneal macrophages from apo $E^{-1-} / \mathrm{L}-12 \mathrm{LO}^{+/-}$mice expressed L-12LO protein (Figure $4 \mathrm{~h}$ ), which is consistent with previous in situ hybridization data (45). Heterogeneity of macrophage L-12LO expression within lesions may exist but was not evaluated in the present study.

\section{Table 1}

Total plasma cholesterol and triglycerides

$\begin{array}{cccc}\text { Genotypes } & \text { Cholesterol }(\mathrm{mg} / \mathrm{dL}) & \text { Triglycerides }(\mathrm{mg} / \mathrm{dL}) & \\ \text { Apo } E^{-/-} / \mathrm{L}-12 L O^{+/+} & 531 \pm 28 & 113 \pm 19 & n=9 \\ \text { Apo } E^{-/-} / \mathrm{L}-12 L O^{+/-} & 578 \pm 41 & 156 \pm 37 & n=10 \\ \text { Apo } E^{-/-} / \mathrm{L}-12 L O^{-/-} & 620 \pm 96 & 148 \pm 28 & n=10\end{array}$

Data are expressed as the mean \pm SEM. Cholesterol and triglyceride levels were not significantly different between genotypes: $P=0.43$ by Kruskal-Wallis nonparametric ANOVA and $P=0.56$ by one-way ANOVA, respectively. 

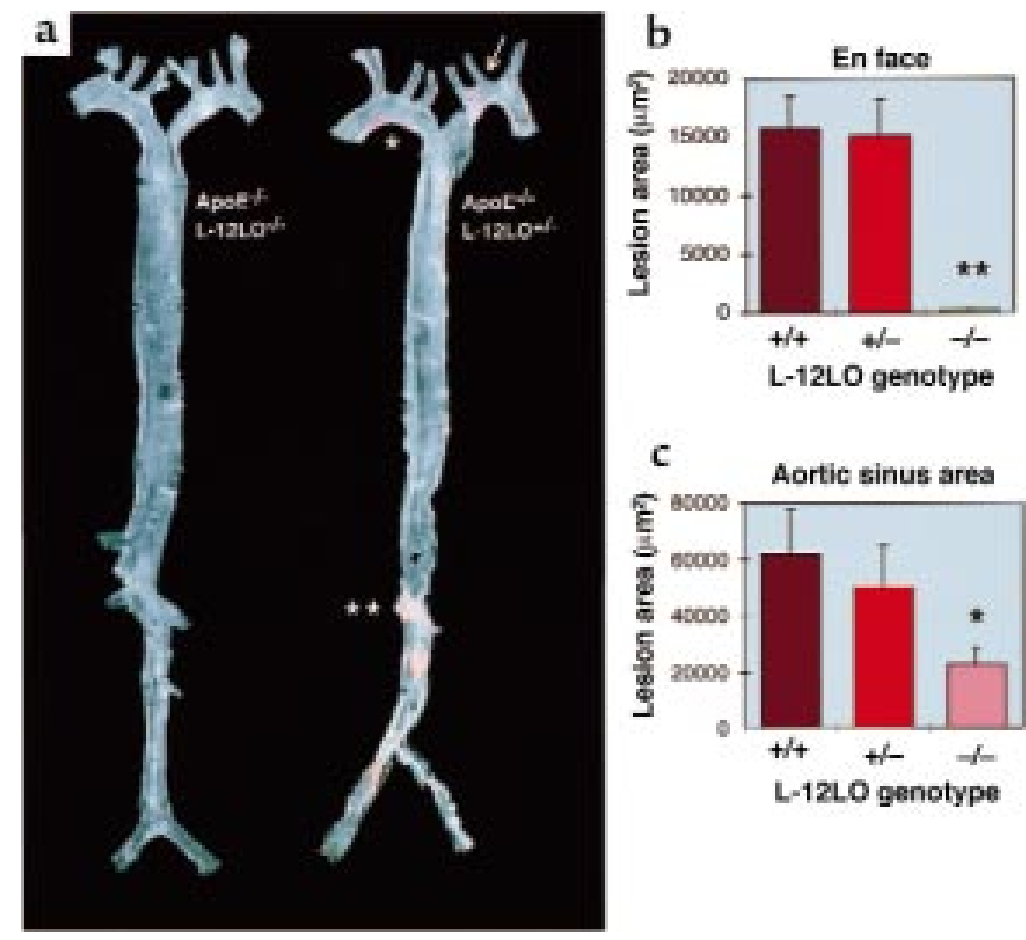

\section{Figure 3}

12/15-lipoxygenase deficiency results in diminished fatty lesions in apo E-deficient mice. (a) Representative Sudan IV-stained aortas of an apo $E^{-/-} / \mathrm{L}-12 \mathrm{LO}^{-/-}$double-knockout mouse (left) and an apo E knockout mouse heterozygous for L-12LO (right). Mice were raised on a normal chow diet and sacrificed at 15 weeks of age $(n=12)$. Atheromatous plaques have already developed in the lesser curvature of the aortic arch (asterisk), at the ostia of the left common carotid artery, and the left subclavian artery (arrow), as well as in the abdominal aorta between the ostia of the left and right renal artery (double asterisk), whereas the aorta of the double-knockout mouse remains free of any lesion development at this age. (b and c) Atherosclerotic average lesion area in en face preparations $(n=12$ per group) (b) and aortic sinus areas ( $n=12$ for $L-12 L O^{+/-}$ and $L-12 L O^{-/-} ; n=9$ for $\left.L-12 L O^{+/+}\right)(c)$ in apo $E^{-/-}$mice

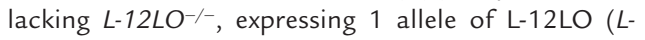
$\left.12 \mathrm{LO}^{+/-}\right)$, or expressing both alleles $\left(\mathrm{L}-12 \mathrm{LO}^{+/+}\right)$. Mice fed a normal chow diet were sacrificed at 15 weeks of age. Values are mean \pm SEM. ${ }^{* *} P<0.0001$ ( $t$ test). For comparison between groups in $\mathrm{c}:{ }^{*} P=0.015$ for $L-12 \mathrm{LO}^{+/+}$ vs. $L-12 L^{-/-}$(Mann-Whitney test), $P=0.10$ for $L-$ $12 \mathrm{LO}^{+/-}$vs. $\mathrm{L}-12 \mathrm{LO}^{-/-}$(Mann-Whitney test), and $P=$

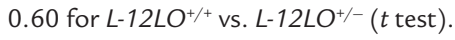

To delineate the time dependency of lesion development, apo $E^{-/-} / L-12 L O^{-/-}$double-knockout mice and apo $E^{-/-} / \mathrm{L}-12 \mathrm{LO}^{+/-}$mice were maintained on a normal mouse-chow diet for a period of 1 year. En face preparations of their aortas demonstrated significantly enhanced lesion development in the apo $\mathrm{E}^{-/-} / \mathrm{L}-12 \mathrm{LO}^{+/-}$ heterozygous mice $\left(209,997 \pm 80,864 \mu \mathrm{m}^{2}\right)$ as compared with the apo $E^{-/-} / L-12 \mathrm{LO}^{-/-}$double-knockout mice $\left(90,125 \pm 23,034 \mu \mathrm{m}^{2} ; n=10, P<0.0001\right.$, Mann-Whitney test). However, the latter group of mice now shows substantial lesion development as opposed to that observed at the 15-week time point (Figure 5).

Autoantibodies against ox $L D L$ are diminished in apo $E^{-/-} / L$ $12 \mathrm{LO}^{-/-}$double-knockout mice. When LDL undergoes oxidative modification and atherosclerosis occurs, a variety of neoepitopes are formed that result in autoantibody formation (13). In cholesterol-fed LDL receptor-deficient mice, the titer of autoantibodies to an epitope of oxLDL correlated significantly with the extent of atherosclerosis (50). Antibodies can be detected with oxLDL itself as an antigen or by using a model epitope such as MDA-LDL. Using a solid-phase chemiluminescent immunoassay, we measured the titers of anti-oxLDL and anti-MDA-LDL antibodies in the plasma of mice and sought to correlate the titers to the extent of lesions quantitated by the en face method. There were no differences in IgM antibody titers. However, there were significantly elevated titers of IgG to both antigens in apo $E^{-/-} / \mathrm{L}-12 \mathrm{LO}^{+/-}$mice as compared with apo $E^{-/-} / \mathrm{L}^{-12} \mathrm{LO}^{-/-}$ double-knockout mice (Figure 6; 1,931 \pm 435 vs. $787 \pm$ 161 for MDA-LDL, and $378 \pm 116$ vs. $145 \pm 36$ for oxLDL; RLU $/ 100 \mathrm{~ms}, n=9$ and $n=15$, respectively; $P<$ $0.05, t$ test). These results correlate with the increased degree of lesion progression in the mice expressing 1 allele of L-12LO $(r=0.64, P=0.01$ for oxLDL antibody data; $r=0.54, P=0.045$ for MDA-LDL antibody data).

\section{Discussion}

These studies have addressed the in vivo role of $12 / 15$-lipoxygenase in atherogenesis in the apo $E^{-/-}$ mouse model of atherosclerosis. Apo $E^{-/-} / L_{-1} 12 \mathrm{LO}^{-/-}$double-knockout mice at 15 weeks of age on a normal chow diet displayed no significant atherosclerotic lesions in whole-aorta en face preparations, in strong contrast to the apo $E^{-/-} / L-12 \mathrm{LO}^{+/-}$heterozygous and apo $E^{-/-} / L-12 \mathrm{LO}^{+/+}$control mice. Expression of 1 allele of the L-12LO gene was apparently sufficient to yield similar lesion size in mice expressing 2 copies of the L-12LO gene on an apo E-deficient background, indicating no gene dosage effects. These lesion data are even more compelling because the total cholesterol and triglyceride levels, as well as the lipoprotein profiles, were similar among all groups of animals. Interestingly, although still statistically significant, the difference in atherosclerotic lesions in the aortic sinus region, as measured by section analysis, was less striking than that seen in the en face preparations of the distal aorta. In apo E-deficient mice, lesions in the aortic sinus area are among the most prominent early sites of predilection (51); thus, lesions there are usually the most advanced at any subsequent time they are measured. The reasons for this are not fully known, but the aortic sinus area may be subjected to higher turbulent flow forces than are distal regions. Thus, turbulent flow-related atherogenic mechanisms could diminish the early protection afforded by absence of macrophage L-12LO expression in the aortic sinus.

These data suggest that lipoxygenases are involved in the early stages of atherogenesis. The initial lipid peroxide resulting from the lipoxygenase reaction is stereospecific, but as nonenzymatic lipid peroxidation ensues, the hydroperoxides generated would be increasingly racemic. Indeed, consistent with this idea are the observations that predominantly stereospecific arachi- 

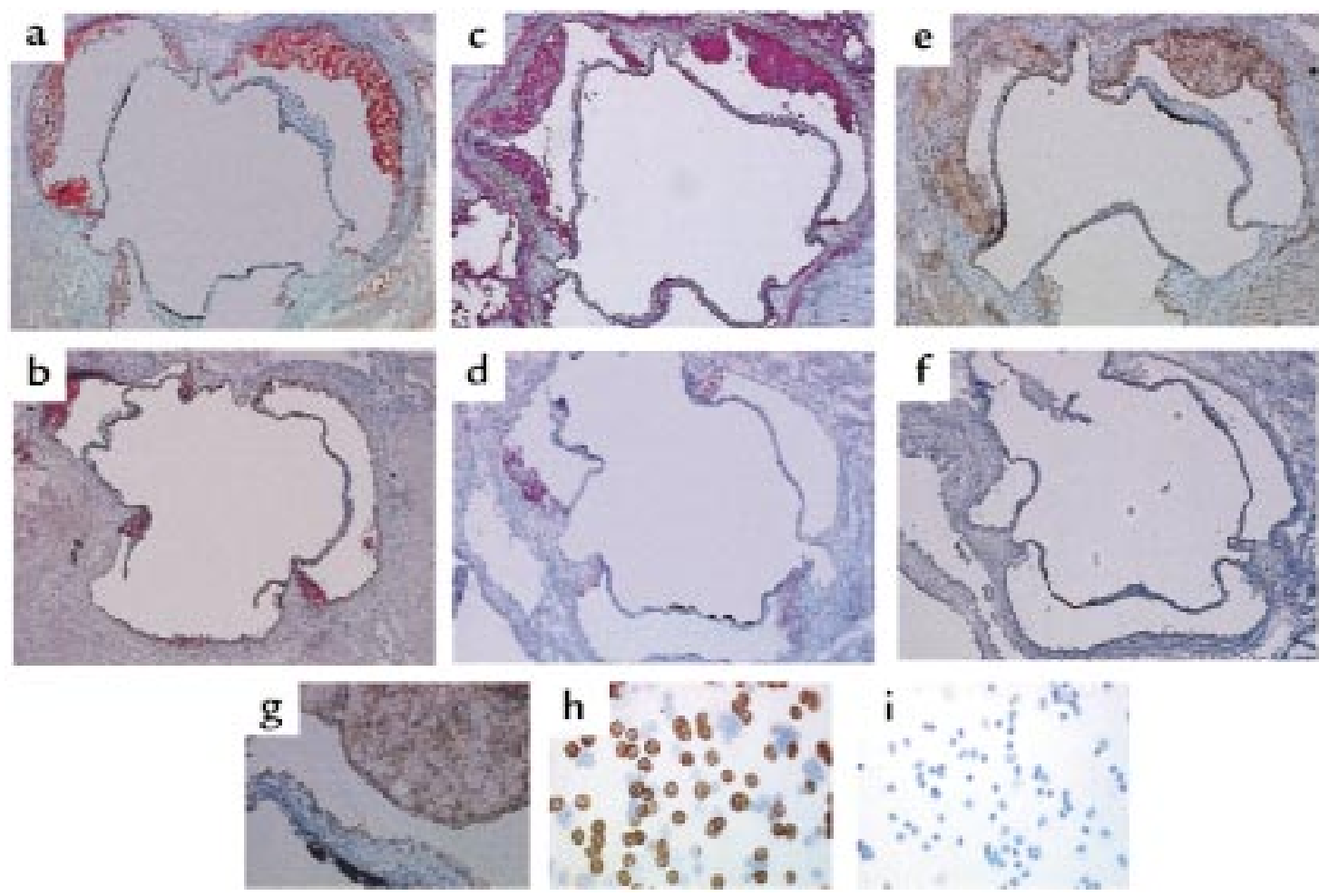

\section{Figure 4}

Analysis of lesions and L-12LO protein in aortic sinus sections and macrophages. (a-g) Aortic sinus sections from an apo $E^{-/-} / L-12 L O^{+/-}$mouse $(\mathbf{a}$, $\mathbf{c}, \mathbf{e}$, and $\mathbf{g}$; total lesion area $\left.=60,930 \mu \mathrm{m}^{2}\right)$ and an apo $E^{-/-} / L-12 L O^{-/-}$double-knockout mouse $\left(\mathbf{b}, \mathbf{d}\right.$, and $\mathbf{f}$; total lesion area $\left.=16,129 \mu \mathrm{m}^{2}\right)$ were stained for lipid lesions (oil red O) ( $\mathbf{a}$ and $\mathbf{b}$ ) and immunostained for macrophage content (MOMA-2 antibody) (c and d) and for 12/15-lipoxygenase (polyclonal antibody against L-12LO) $(\mathbf{e}-\mathbf{g})$. The image in $\mathbf{g}$ is magnified from the upper-right lesion in $\mathbf{e}$ to show foamy macrophage composition. Sections are not adjacent but are within the first $300 \mu \mathrm{m}$ of the proximal aorta, starting at the aortic sinus. Peritoneal macrophages were also immunostained with antibody against L-12LO (h and $\mathbf{i})$. Macrophages from a double-knockout animal (i) do not express 12-lipoxygenase, and about $40 \%$ of the macrophages from an apo $E^{-1-} / \mathrm{L}-12 \mathrm{LO}^{+/-}$mouse $(\mathbf{h})$ express $\mathrm{L}-12 \mathrm{LO}$, which is consistent with previous in situ hybridization data (45). More than $98 \%$ of the cells in this figure are macrophages.

donate and linoleate metabolites are found in early atherosclerotic lesions (37-39). More advanced lesions show a racemic mixture of metabolites indicative of nonenzymic lipid peroxidative processes. Thus, once early macrophage-laden subintimal deposits are "seeded" with lipoxygenase-derived hydroperoxides (initiation phase), the oxidized lipids that subsequently accumulate increasingly reflect an independent pathway. Our results corroborate these findings, because at 15 weeks, at a time early in fatty streak development in the apo E-deficient mouse model, we observed such striking differences. To delineate further the time dependency of lipoxygenase involvement in atherogenesis in vivo, we examined lesion development in apo $E^{-/-} / \mathrm{L}_{-1} 12 \mathrm{LO}^{-/-}$double-knockout mice and apo $E^{-/ /} / \mathrm{L}-12 \mathrm{LO}^{+/-}$heterozygous mice that were maintained on a normal mouse-chow diet for 1 year. A significant difference in lesion development still remains between the 2 groups, although the apo $E^{-/-} / \mathrm{L}-12 \mathrm{LO}^{-/-}$double-knockout mice now show substantial atherosclerosis in the en face preparations. This result could indicate that lipoxygenase expression still plays a role in lesion development in later stages of disease progression. Alternatively, once the early stage is influenced by gene disruption, there could be a dramatic alteration of ensuing events in older mice that limits progression of lesion development.
In mice, L-12LO is most highly expressed in macrophages isolated from the peritoneal cavity (45). In humans, the corresponding 15-lipoxygenase is highly expressed in monocytes treated with IL-4 $(23,52)$ or IL-13 $(23,53)$ and in reticulocytes (54). Disruption of the mouse gene leads to blockade of 12-HETE and 15HETE formation from arachidonic acid, with some shunting of substrate to the 5-lipoxygenase pathway (45). L-12LO-deficient macrophages incubated with LDL do not show any differences in terms of lipid peroxidation compared with wild-type macrophages incubated with LDL (45). However, when stimulated with zymosan, these macrophages demonstrate a decreased ability to modify LDL in the medium, as measured by isoprostane $\mathrm{iPF}_{2} \alpha$-III (formerly known as 8-epi- $\mathrm{PGF}_{2} \alpha$ ; ref. 55) or thiobarbituric acid-reactive substances, when compared with wild-type macrophages. In the current study, we found evidence that serum autoantibodies against oxLDL epitopes of the IgG class were substantially reduced in apo $E^{-/-} / \mathrm{L}^{-1} 12 \mathrm{LO}^{-/-}$mice compared with control apo $E^{-/-} / L-12 L O^{+/-}$mice. This apparent correlation of lipoxygenase activity and oxLDL autoantibodies suggests that autoantibodies against oxLDL, like isoprostanes, may be useful as markers for enhanced lipid peroxidation and thus enhanced susceptibility to atherogenesis. 


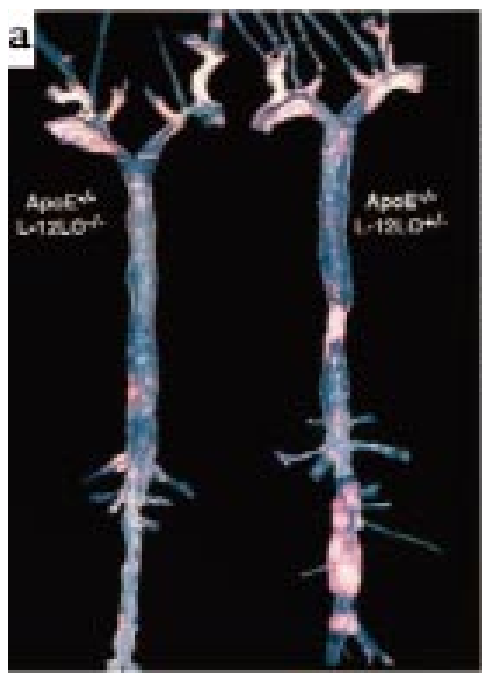

b

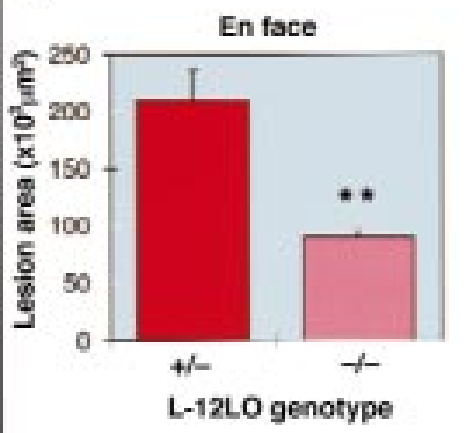

Figure 5

12/15-lipoxygenase deficiency delays progression of lesion development in apo E-deficient mice. (a) Representative Sudan IV-stained aortas of an apo $E^{-/-} / \mathrm{L}-12 \mathrm{LO}^{-/-}$doubleknockout mouse (left) and an apo $E$ knockout mouse heterozygous for L-12LO (right). Mice were raised on a normal chow diet and sacrificed at 1 year of age $(n=12$ and $n=10$, respectively). Atheromatous plaques are at a much more advanced stage in the apo $E^{-/-} / \mathrm{L}-12 \mathrm{LO}^{+/-}$group and include large parts of the thoracic and abdominal aorta, with near occlusion in the renal artery area. (b) Atherosclerotic average lesion area in en face preparations at 1 year of age. Values are mean \pm SEM. ${ }^{* *} P<0.0001$ (Mann-Whitney test).
A study of overexpression of 15-lipoxygenase in rabbit iliac arteries indicated that the enzyme might promote atherogenesis (56). The occurrence of oxLDL epitopes was demonstrated in the transfected areas as compared with the contralateral sham-transfected iliac artery (56). Furthermore, in 2 recent publications, it was found that a 15-lipoxygenase inhibitor, PD146176, attenuated the progression of atherosclerosis and monocyte-macrophage enrichment of lesions in hypercholesterolemic rabbits in the absence of changes in plasma total or lipoprotein cholesterol $(42,43)$, although there was no direct proof of enzyme inhibition in vivo. However, in another study, a different result was found when transgenic rabbits were generated that overexpressed 15-lipoxygenase in macrophages under control of a lysozyme promoter. These rabbits appeared to develop less atherosclerosis in 2 of 3 experiments (44). The reasons for the differences among these studies are not clear at present.

What could be the mechanisms intertwining 12/15lipoxygenase, oxidation of LDL, and atherosclerosis lesion development? The 12/15-lipoxygenases are cytosolic intracellular enzymes that can interact with plasma membrane or intracellular sites to access their substrate. However, approach to extracellular LDL would be difficult unless the enzyme could be released from macrophages in the microenvironment of the subintimal space. This, however, has not yet been demonstrated. More likely is the possibility that lipoxygenase-derived hydroperoxides or secondary reactive lipid species may be transferred across the cell membrane to "seed" the extracellular LDL, which would then be more susceptible to a variety of mechanisms that could promote lipid peroxidation. Indeed, it has been shown that LDL incubated with 15-lipoxygenase-transfected fibroblasts has an increased content of lipid hydroperoxides and biological properties of minimally oxidized LDL (57-59).

An alternative model is that activation of the 12/15-lipoxygenase pathway in newly recruited monocytes/macrophages provide 12/15-HETE or 13-hydroxy-octadecadienoic acid ligands for PPAR- $\gamma$, which in turn activates transcription of CD36, one of the receptors for oxLDL, and leads to enhanced oxLDL uptake $(24,60,61)$. Another possibility from these studies with the 12/15-LO gene-disrupted mice is the compensatory change in other pathways that might influence lesion development. Previously, with in vitro macrophage incubations, we found evidence for enhanced 5 -lipoxygenase product formation. This was not a gene regulatory event, but a diversion of substrate arachidonic acid to this pathway. With the advent of mouse atherosclerotic models described here, it should be possible to address some of these various mechanistic issues.

In conclusion, we have generated evidence that a lipoxygenase enzyme plays an important role in the development of atherosclerosis in vivo. L-12LO deficiency reduces lesion development in apo E-deficient mice and leads to a reduction in the formation of antibodies directed against oxLDL epitopes, but does not substantially alter plasma cholesterol levels. It remains to be determined whether specific 12/15-lipoxygenase inhibitors could prove beneficial for early atherosclerosis intervention.

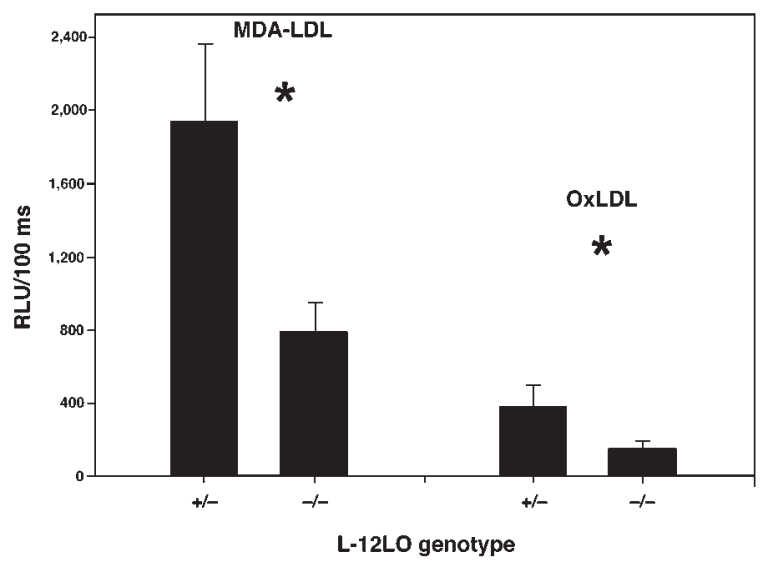

\section{Figure 6}

Diminished titers of antibodies directed toward oxLDL epitopes in apo $E^{-/-} \mathrm{L}-12 \mathrm{LO}^{-/-}$mice. Solid-phase chemiluminescent immunoassays of autoantibodies to oxLDL and MDA-LDL epitopes in plasma samples of apo $E^{-/-} / L-12 L^{+/-}$and apo $E^{-/-} / L-12 L O^{-/-}$mice $(n=9$ and $n=15$, respectively; mean \pm SEM). ${ }^{*} P=0.008$ for autoantibody titers to MDA-LDL, and $P=0.03$ for autoantibody titers to oxLDL $(t$ test $)$. Data are expressed as relative light units per 100 milliseconds (RLU/100 ms). 


\section{Acknowledgments}

We wish to thank L.A. Gleaves and P. Smith for expert technical assistance. This work was supported by an Else Kroener-Stiftung grant (to T. Cyrus) and National Institutes of Health grants HL53558 (to C.D. Funk), HL-59694 (Specialized Center of Research, to J.L. Witztum), and GM-15431 (to M.F. Linton and S. Fazio).

1. Peters, K.D., Kochaneck, K.D., and Murphy, S.L. 1998. Deaths: final data for 1996. Natl. Vital Stat. Rep. 47:2-6.

2. Steinberg, D., Parthasarathy, S., Carew, T.E., Khoo, J.C., and Witztum, J.L. 1989. Beyond cholesterol. Modifications of low-density lipoprotein that increase its atherogenicity. N. Engl. J. Med. 320:915-924.

3. Steinberg, D. 1997. Low density lipoprotein oxidation and its pathobiological significance. J. Biol. Chem. 272:20963-20966.

4. Berliner, J.A., and Heinecke, J.W. 1996. The role of oxidized lipoproteins in atherogenesis. Free Radic. Biol. Med. 20:707-727.

5. Henriksen, T., Mahoney, E.M., and Steinberg, D. 1981. Enhanced macrophage degradation of low density lipoprotein previously incubated with cultured endothelial cells: recognition by receptors for acetylated low density lipoproteins. Proc. Natl. Acad. Sci. USA. 78:6499-6503.

6. Steinbrecher, U.P., Parthasarathy, S., Leake, D.S., Witztum, J.L., and Steinberg, D. 1984. Modification of low density lipoprotein by endothelial cells involves lipid peroxidation and degradation of low density lipoprotein phospholipids. Proc. Natl. Acad. Sci. USA. 81:3883-3887.

7. Morel, D.W., DiCorletto, P.E., and Chisolm, G.M. 1984. Endothelial and smooth muscle cells alter low density lipoprotein in vitro by free radical oxidation. Arteriosclerosis. 4:357-364.

8. Heinecke, J.W., Rosen, H., and Chait, A. 1984. Iron and copper promote modification of low density lipoprotein by human arterial smooth muscle cells in culture. J. Clin. Invest. 74:1890-1894.

9. Parthasarathy, S., Printz, D.J., Boyd, D., Joy, L., and Steinberg, D. 1986. Macrophage oxidation of low density lipoprotein generates a modified form recognized by the scavenger receptor. Atherosclerosis. 6:505-510.

10. Ylä-Herttuala, S., et al. 1989. Evidence for the presence of oxidatively modified low density lipoprotein in atherosclerotic lesions of rabbit and man. J. Clin. Invest. 84:1086-1095.

11. Palinski, W., et al. 1989. Low density lipoprotein undergoes oxidative modification in vivo. Proc. Natl. Acad. Sci. USA. 86:1372-1376.

12. Suarna, C., Dean, R.T., May, J., and Stocker, R. 1995. Human atherosclerotic plaque contains both oxidized lipids and relatively large amounts of alpha-tocopherol and ascorbate. Arterioscler. Thromb. Vasc. Biol. 15:1616-1624.

13. Palinski, W., et al. 1994. ApoE deficient mice are a model of lipoprotein oxidation in atherogenesis. Arterioscler. Thromb. 14:605-616.

14. Hörkkö, S., Miller, E., Branch, D.W., Palinski, W., and Witztum, J.L. 1997. The epitopes for some antiphospholipid antibodies are adducts of oxidized phospholipid and beta2 glycoprotein 1. Proc. Natl. Acad. Sci. USA. 94:10356-10361.

15. Praticó, D., et al. 1998. $\mathrm{IPF}_{2 \alpha}$-I: an index of lipid peroxidation in humans. Proc. Natl. Acad. Sci. USA. 95:3449-3454.

16. Praticó, D., et al. 1997. Localization of distinct F2-isoprostanes in human atherosclerotic lesions. J. Clin. Invest. 100:2028-2034.

17. Praticó, D., Tangirala, R.K., Rader, D.J., Rokach, J., and FitzGerald, G.A. 1998. Vitamin E suppresses isoprostane generation in vivo and reduces atherosclerosis in ApoE-deficient mice. Nat. Med. 10:1189-1192.

18. Witztum, J.L. 1994. The oxidation hypothesis of atherosclerosis. Lancet. 344:793-795.

19. Navab, M., et al. 1996. The Yin and Yang of oxidation in the development of the fatty streak. Arterioscler. Thromb. Vasc. Biol. 16:831-842.

20. Quinn, M.T., Parthasarathy, S., Fong, L.G., and Steinberg, D. 1987. Oxidatively modified low density lipoproteins: a potential role in recruitment and retention of monocyte/macrophages during atherogenesis. Proc. Natl. Acad. Sci. USA. 84:2995-2998.

21. Cushing, S.D., et al. 1990. Minimally modified low density lipoprotein induces monocyte chemotactic protein 1 in human endothelial cells and smooth muscle cells. Proc. Natl. Acad. Sci. USA. 87:5134-5138.

22. Watson, A.D., et al. 1997. Structural identification by mass spectrometry of oxidized phospholipids in minimally oxidized low density lipoprotein that induce monocyte/endothelial interactions and evidence for their presence in vivo. J. Biol. Chem. 272:13597-13607.

23. Folcik, V.A., Aamir, R., and Cathcart, M.K. 1997. Cytokine modulation of LDL oxidation by activated human monocytes. Arterioscler. Thromb. Vasc. Biol. 17:1954-1961.

24. Nagy, L., Tontonoz, P., Alvarez, J.G., Chen, H., and Evans, R.M. 1998. Oxidized LDL regulates macrophage gene expression through ligand activation of PPARgamma. Cell. 93:229-240.

25. Parthasarathy, S., Wieland, E., and Steinberg, D. 1989. A role for endothelial cell lipoxygenase in the oxidative modification of low density lipoprotein. Proc. Natl. Acad. Sci. USA. 86:1046-1050.

26. Kühn, H., Belkner, J., Suzuki, H., and Yamamoto, S. 1994. Oxidative modification of human lipoprotein by lipoxygenases of different positional specificities. J. Lipid Res. 35:1749-1759.

27. Yamamoto, S. 1992. Mammalian lipoxygenases: molecular structures and functions. Biochim. Biophys. Acta. 1128:117-131.

28. Funk, CD. 1996. The molecular biology of mammalian lipoxygenases and the quest for eicosanoid functions using lipoxygenase-deficient mice. Biochim. Biophys. Acta. 1304:65-84.

29. Belkner, J., Stender, H., and Kühn, H. 1998. The rabbit 15-lipoxygenase preferentially oxygenates LDL cholesterol esters, and this reaction does not require vitamin E. J. Biol. Chem. 273:23225-23232.

30. Takahashi, Y., et al. 1993. Investigation of the oxygenation of phospholipids by the porcine leukocyte and human platelet arachidonate 12lipoxygenases. Eur. J. Biochem. 218:165-171.

31. Sloane, D.L., Leung, R., Craik, C.S., and Sigal, E. 1991. A primary determinant for lipoxygenase positional specificity. Nature. 354:149-152.

32. Chen, X.S., Kurre, U., Jenkins, N.A., Copeland, N.G., and Funk, C.D. 1994. cDNA cloning, expression, mutagenesis of C-terminal isoleucine, genomic structure, and chromosomal localizations of murine 12-lipoxygenases. J. Biol. Chem. 269:13979-13987.

33. Borngraber, S., Kuban, R.J., Anton, M., and Kühn H. 1996. Phenylalanine 353 is a primary determinant for the positional specificity of mammalian 15-lipoxygenases. J. Mol. Biol. 264:1145-1153.

34. Ylä-Herttuala, S., et al. 1990. Colocalization of 15-lipoxygenase mRNA and protein with epitopes of oxidized low density lipoprotein in macrophage-rich areas of atherosclerotic lesions. Proc. Natl. Acad. Sci. USA. 87:6959-6963.

35. Ylä-Herttuala, S., et al. 1991. Gene expression in macrophage-rich human atherosclerotic lesions. 15-lipoxygenase and acetyl low density lipoprotein receptor messenger RNA colocalize with oxidation specific lipid-protein adducts. J. Clin. Invest. 87:1146-1152.

36. Hiltunen, T., Luoma, J., Nikkari, T., and Ylä-Herttuala, S. 1995. Induction of 15-lipoxygenase mRNA and protein in early atherosclerotic lesions. Circulation. 92:3297-3303.

37. Kühn, H., Belkner, J., Zaiss, S., Fährenklempner, T., and Wohlfeil, S. 1994. Involvement of 15-lipoxygenase in early stages of atherogenesis. J. Exp. Med. 179:1903-1911.

38. Folcik, V.A., Nivar-Aristy, R.A., Krajewski, L.P., and Cathcart, M.K. 1995. Lipoxygenase contributes to the oxidation of lipids in human atherosclerotic plaques. J. Clin. Invest. 96:504-510.

39. Kühn, H., Heydeck, D., Hugou, I., and Gniwotta, C. 1997. In vivo action of 15-lipoxygenase in early stages of human atherogenesis. J. Clin. Invest. 99:888-893

40. Kühn, H., and Chan, L. 1997. The role of 15-lipoxygenase in atherogenesis: pro- and antiatherogenic actions. Curr. Opin. Lipidol. 8:111-117.

41. Feinmark, S.J., and Cornicelli, J.A. 1997. Is there a role for 15-lipoxygenase in atherogenesis? Biochem. Pharmacol. 54:953-959.

42. Sendobry, S.M., et al. 1997. Attenuation of diet-induced atherosclerosis in rabbits with a highly selective 15-lipoxygenase inhibitor lacking significant antioxidant properties. Br. J. Pharmacol. 120:1199-1206.

43. Bocan, T., et al. 1998. A specific 15-lipoxygenase inhibitor limits the progression and monocyte-macrophage enrichment of hypercholesterolemiainduced atherosclerosis in the rabbit. Atherosclerosis. 136:203-216.

44. Shen, J., et al. 1997. Macrophage-mediated 15-lipoxygenase expression protects against atherosclerosis development. J. Clin. Invest. 98:2201-2208.

45. Sun, D., and Funk, C.D. 1996. Disruption of 12/15-lipoxygenase expression in peritoneal macrophages. Enhanced utilization of the 5-lipoxygenase pathway and diminished oxidation of low density lipoprotein. J. Biol. Chem. 271:24055-24062.

46. Plump, A.S., et al. 1992. Severe hypercholesterolemia and atherosclerosis in apolipoprotein E-deficient mice created by homologous recombination in ES cells. Cell. 71:343-353.

47. Linton, M.F., Atkinson, J.B., and Fazio, S. 1995. Prevention of atherosclerosis in apolipoprotein E-deficient mice by bone marrow transplantation. Science. 267:1034-1037.

48. Leenen, P.J., de Bruijn, M.F., Voerman, J.S., Campbell, P.A., and van Ewijk, W. 1994. Markers of mouse macrophage development detected by monoclonal antibodies. J. Immunol. Methods. 174:5-19.

49. Zhang, H.S., Reddick, R.L., Piedrahita, J.A., and Maeda, N. 1992. Spontaneous hypercholesterolemia and arterial lesions in mice lacking apolipoprotein E. Science. 258:468-471.

50. Palinski, W., Tangirala, R.K., Miller, E., Young, S.G., and Witztum, J.L. 1995. Increased autoantibody titers against epitopes of oxidized LDL in LDL receptor-deficient mice with increased atherosclerosis. Arterioscler. Thromb. Vasc. Biol. 15:1569-1576.

51. Nakashima, Y., Plump, A.S., Raines, E.W., Breslow, J.L., and Ross, R. 1994. ApoE-deficient mice develop lesions of all phases of atherosclerosis throughout the arterial tree. Arterioscler. Thromb. Vasc. Biol. 14:133-140.

52. Conrad, D.J., Kühn, H., Mulkins, M., Highland, E., and Sigal, E. 1992. Specific inflammatory cytokines regulate the expression of human monocyte 15-lipoxygenase Proc. Natl. Acad. Sci. USA. 89:217-221.

53. Nassar, G.M., Morrow, J.D., Roberts, L.J., Lakkis, F.G., and Badr, K.F. 
1994. Induction of 15-lipoxygenase by interleukin-13 in human blood monocytes. J. Biol. Chem. 269:27631-27634.

54. Kroschwald, P., et al. 1989. Occurrence of the erythroid cell specific arachidonate 15-lipoxygenase in human reticulocytes. Biochem. Biophys. Res. Commun. 160:954-960.

55. Rokach, J., et al. 1997. Nomenclature of isoprostanes: a proposal. Prostaglandins. 54:853-873.

56. Ylä-Herttuala, S., Luoma, J., Vilta, H., Hiltunen, T., and Nikkari, T. 1995. Transfer of 15-lipoxygenase gene into rabbit iliac arteries results in the appearance of oxidation-specific lipid-protein adducts characteristic of oxidized low density lipoprotein. J. Clin. Invest. 95:2692-2698.

57. Benz, D.J., et al. 1995. Enhanced levels of lipoperoxides in low density lipoprotein incubated with murine fibroblast expressing high levels of human 15-lipoxygenase. J. Biol. Chem. 270:5191-5197.

58. Ezaki, M., Witztum, J.L., and Steinberg, D. 1995. Lipoperoxides in LDL incubated with fibroblasts that overexpress 15 -lipoxygenase. J. Lipid. Res. 36:1996-2004.

59. Sigari, F., Lee, C., Witztum, J.L., and Reaven, P.D. 1997. Fibroblasts that overexpress 15-lipoxygenase generate bioactive and minimally modified LDL. Arterioscler. Thromb. Vasc. Biol. 17:3639-3645.

60. Tontonoz, P., Nagy, L., Alvarez, J.G., Thomazy, V.A., and Evans, R.M. 1998. PPARgamma promotes monocyte/macrophage differentiation and uptake of oxidized LDL. Cell. 93:241-252.

61. Nozaki, S., et al. 1995. Reduced uptake of oxidized low density lipoproteins in monocyte-derived macrophages from CD36-deficient subjects. J. Clin. Invest. 96:1859-1865. 